mest, then, be located in the carotid canal of the petrous bone, or immediately in the inner side of it.

The patient had yet one other symptom, but not very easily detected, which came on subsequent to the buzzing in the head, and which, when ascertained and properly appreciated, decided the matter. She had slight, very slight paralysis of the external rectus muscle of the left eye; which muscle is supplied by the sixth cranial nerve, which is devoted solely to it. Now, of all the nerves which go to the muscles of the eyeball, the sixth is the only one that passes through the cavernous sinus, the remainder being lodged in the external wall; and it passes through the sinus in direct contact with the external aspect of the internal carotid artery, :mmediately on its emergence from the carotid canal. A small tumour of the vessel in this situation would account for all the symptoms, not only for those having direct reference to the bruit and strabismus, but also for the inability to lie down; the system being as it were conscious of some imminent danger threatening it, and feeling that it was less likely to suffer injury, the weight of the column of blood being restrained from pressing on the aneurism. (The sitting up may be fairly likened to an ordinary automatic consensual action.) It would also explain in some degree the horrid character of the dreams, which were in all probability produced partly by this constant indefinite sense of danger to which $I$ have alluded, and partly by disturbance of the cerebral circulation.

The double vision, when looking with both eyes, was simply owing to the disturbance of the usual axis of vision, produced by the recent and increasing internal strabismus; and the tritling indistinctness of rision was due perhaps to less blood passing through the left ophthalmic artery, thus diminishing the supply to the retina. I am rather inclined

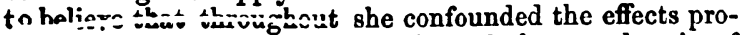
duced by the continual alteration of the usual axis of vision, first in one direction, then in another, with true indistinctness of vision; though there could not be any doubt but that she saw slightly better with the right than the left eye, and just so much better as a comparatively freer arterial supply would account for.

There could, then, be little hesitation in deciding that the case was one of aneurism, and I had little misgiving but that it was in the situation I have stated I thought it was. But, before operating, I said that I should consider somewhat sudden increase of the paralysis of the external rectus muscle, if followed by its gradual and perfect recovery, as the patient improved and time rolled on, to be perfectly confirmatory of the correctness of my opinion; the view I took being, that the existing slight paralysis of the left external rectus muscle was caused by pressure on the sirth nerve, as it crossed the artery, by a small aneurismal tumour, containing principally fluid flood; but that, when the common carotid should be tied, then a clot would form in the tumour, producing harder and firmer pressure on the nerve, and consequently more marked paralysis of the external muscle; and that, as the clot diminished in size, and became absorbed, the pressure would be taken off the nerve, and it would then resume its functions. The after history of the case, as you have heard by the notes, fully bore out this idea.

In reference to the substitution of a gentle almost continuous murmur immediately after ligaturing the vessel, for the loud whizzing sound previously existing - the substitution being recognised by the patient, and by those present at the operation-it was caused, I presume, by a continuance of the passage of blood, but with diminished farce, into the tumour, by means of the circle of Willis. At 4 P.x. of the day of the operation, and about five hours after it, this murmur could no longer be heard either by the patient or myself; and was succeeded in its turn by a crackling noise in the vicinity of the ear, audible only to the patient: this quickly ceased.

In addition to the positive evidence afforded by the symptoms in this case, everything that is known of the pathology of the cerebral vescels, in persons of the age of this patient, tends to show the probability of such a lesion occurring, under the circumstances in which this woman was placed. I allude to Paget's researches on fatty degoneration of the coats of the cerebral arteries; Virchow's romarks on aneurismal dilatation of the same ressels, caused by paralysis of their muscular coat ; to Rokitansky's general investigations on the effects produced by atheromatous doposit on and degeneration of the inner arterial tissues; those cffects being either rupture of those tissues and dilatation of the cellular coat, or laceration of all the costs.

Finally, there are records of the discovery, post mortemen, of aneurism of the interual carotid artery in the cavernous sinus. Romberg, in his work on Diseases of the Nervows System, gives in extenso the history of a most horrible cane of facial neuralgia of the left side, which was ascertained to depend in great degree on pressure of the Casserian ganglion of the same side by an aneurism of the left carotid artery in the cavernous sinus. In 1836, there was published at Berlin a dissertation by Stumpf, De Anevirysmatibus Arteriarum Cerebri. In this he gives two cases of aneurism affecting the internal carotid artery in the cavernous sinus. I have been unable to procure the original dissertation, and only quote from memory a roference made to it.

I hope that the account of the symptoms of this case, prior and subsequent to the operation, taken in connexion with the known pathology of the cerebral vessels, will lead you to believe that the diagnosis was a correct one, and the treatment adopted not only justifiable, but imperatively called for.

I may state, that I have seen the woman within this week; that she still continues well; and that, in fact, she expresses herself as feeling much better than she did bofore her illness.

\section{TWO CASES OF ABSCESS OF THE NECK, WHICH OPENED INTO THE TRACHEA.}

By GEORGE POUND, Esq., Odiham.

Ox the 25th of July, 1853, I was requested by a woman, who lived in a village two or three miles from hence, to $\mathrm{go}$ and see her child, who had been ill for a week or ten days with hooping-cough. I was informed that on the 23rd (two days previous) the child, who was two and a-half years old, had been seized with a paroxysm of coughing, more than usually severe, and that immediately after, a swelling was perceived over the upper part of the chest, and extending to the side of the neck and face. On visiting the patient, I found as the mother had said, in addition to a severe attack of hooping-cough, a distinctly circumscribed swelling, situated over the upper part and in front of the sternum, nearly as large as an inverted tea-cup, very hard, but not particularly tender. The swelling, which was described as extending up the neck and jaw, had disappeared. The pulse was quick, tonguc furred, breath very offensive, bowels confined. I ordered an aperient, to be followed by saline pectoral medicine, and a blister to be applied over the swelling. I found, on my second visit, that the swelling had shifted its position, and was now placed directly in front of the trachea; that it was soft and fluctuating, and about the size of a hen's egg. The child was very flushed, its breathing quick and laboured; tongue more coated than before, and the odour of the breath most offensive. The bowrel had been frecly moved. There was expectoration of small quantities of blood mixed with matter. Having made opening into the swelling, half a teacupful of very offenaive pus was evacuated, mixed with bubbles of air, showing that the abscess had already opened into the windpipe. The puncture gave immediate relief. By August ind (the last entry relating to the case in my note book) the wound had nearly closed, and the patient was fast gotting better.

About two years after, viz., on the 6th June, 1855, I wes sent for in great haste to go and see A. B., a girl, aged is years, who was said to have romited blood. I found the 
mingt reolining on a temporary bed, in the same position The in when the so-called romiting occurred. On the foor was a large pool of blood, apparently mired with matter. There was a considerable swelling in front, and to the right side of the traches, which fluctuated freely, and occupied the whole of the inferior division of the anterior triangle of the neck. It had been coming about a woek, commencing with hest and tenderness, and some constitutional disturbance. Since the discharge, the swelling had diminished in size; the breathing, which all day had been difficult, was now somewhat relieved. The child, directly after the loss of blood, had been very faint, but had by this time rallied. There was a constant expectoration of thick matter, tinged with blood. There was evidently a considerable abscess, which had opened into the trachea, and laid open an artery, or a considerable branch, as well. I ordered the child to be kept very quiet, to take nothing warm, and that I should be summoned immediately if any more urgent symptoms should come on.

Passing the house a few hours after, I called. The child seemed easy; no difficulty of breathing; no more hæmorrhage than what I before mentioned as tinging the expectorated matter, and the swelling appeared diminishing. I hoped for the best; but the child died suddenly early the next morning. Having fallen asleep, and being awoke by a cense of suffocation, he had coughed up a great quantity of blood, and died, before the mother could summon aid. I made a post mortem examination of the part two days after. On turning back the skin and cervical fascia, a great quantity of coagulated blood was discovered; this being cleared away, the cavity of the abscess was found to extend to the right side of, and behind the upper part of the trachea and the os hyoides, opening into the former at the back, opposite the third or fourth ring. The hæmorrhage proceeded from a branch of the superior thyroid artery.

I do not think I should have been justified, however unfortunate the termination of this case was, in attempting any operative measure; the uncertainty as to the source of the hæmorrhage was so great. It might have been from the superior or inferior thyroid arteries of either side, or from the carotid of the right side: and it would have been a hazardous proceeding to have laid open the cavity of the abscess, now filled with coagulum, and searched for the bleeding vessels, the patient already much exhausted by the preceding hxmorrhage. Besides which, the child's state seemed to farour the hope that she might yet do well; the swelling had diminished, and so had the difficulty of breathing, whilst the hæmorrhage at the time of $\mathrm{my}$ two visits was very slight indeed.

\section{CASE OF COMA WITH PNELMONIA IN A CHILD.}

By H. PAYNE, M.D., Barnsley.

Or the 20th October last, I was called at 11 o'clock P.M. to the infant daughter of Mr. G. Ward, of this town, aged $1 \frac{1}{2}$ year, to give my opinion as to the nature of the disease uader which it was suffering; Dr. Jackson, who was in attendance, having a different opinion from one expressed by a surgeon who had seen the child on the same day, during his absence. I found the child speechless, and in a state bordering on profound coma; the pupils being dilated, insensible to light, and fixed; eyelids closed. Slight cough. Expiration attended with a little grunting effort and noise, indicative of pulmonary disease. Respiratory murmur faint, and nearly absent. Pustules on chest, from use of ung. antim. Face flushed. Pulse 120, strong. Bowels and urinary bladder free. Had never had a fit nor seizure before. In the absence of vomiting, strabismus, and scrofulous symptoms, I directly diagnosed a state of coma, arising from venous congestion caused by pneumonia. As the child could swallow, isinglass and milk were given. The port wine which it was taking to be omitted. Appli- cotur stupe sinspis part. inferiori corporis per sextam part. hore.

Habeat mist. scillø cum sp. æth. nitr. Cap. pulv, antim. gr. ss nocte maneque ad iv vices.

Oct. 21st. Was sensible to the sinapism. Stupor continues. Expectoration copious. Restless when coughing. Contin. mist.

App. sinapis. nuchæ. Habeat ol. ricini coch. parv.

Oct. 23rd. The lethargic states continues. Cough troublesome. Applic. sinap. carpis.

Bo Iod. potass. gr. iv: syr. croci $\zeta s s$; aquæ dest. $j$. M. Cap. coch. parv. ter die.

Rep. pulv. antim. iv.

Oct. 24th. Expectoration stiii frec. ज̈̈üpo: the soms, but pupils contracted and insensible. Takes little support, preferring cold milk.

Oct. 25th. Stupor much less. The child now cries when coughing. Pupils sensitive. There is considerable colic, which a few teaspoonfuls of rue tea, and the addition of tinct. card. co. to the iodine mixture, removed.

Oct. 26th. The stupor has passed off, leaving a feeble fretful state. Coughs little. Takes solid food, and can sit up. To have a teaspoonful occasionally of wine whey.

The iodine mixture was continued up to the lst instant, when, a few boils appearing, it was discontinued. It was given as a stimulant.

Nov. 12th. The father of the child informs me that it is recovering, though slowly; and has several times been out of doors.

Nor. 15th. It is now well.

RExarks. There are three diseases with which this comatose condition in children may be confounded; viz., hydrocephalus, inflammation of the brain. and remittent fever. A careful scrutiny will suffice to distinguish the above symptoms of venous congestion from those of ramollissement, excited arterial action, or serous effusion. In the above case, the respiration afforded the surest guide to a pneumonic affection, which the parents, indeed, could trace to the child having taken cold.

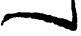

\section{CASE OF PUERPERAL CONVULSIONS.}

By H. J. WATERLAND, Esq., Kirton Lindsey.

ON the 18th of July last, about 5 P.M., I was called to Mrs. R., aged 28 years, primipara, who was then in labour. I found that pains had commenced early that morning, and were proceeding steadily, and that the os uteri was partially dilated; all the signs were then favourable ones. The patient, for the latter months of pregnancy, had been much harassed by nausea and vomiting, with confined bowels; so that scarcely a day had passed without her rejecting the contents of the stomach. From a strong aversion to medicine, she had taken no aperients of any kind: recently she often drank two or three glasses of porter daily, finding no article of drink or food agree with her so well. She had also completely neglected outdoor exercise. There had been spontaneous diarrhoea that morning and the day before. Her temperament seemed lymphatic; her conformation was short and stout; her complexion very clear and fair, but pale; her sensitiveness to pain appeared very acute; the pulse habitually rather weak.

The labour seemed to progress in every respect farourably, until about half-past eleven, or a quarter to midnight; the head of the child then beginning to press upon the perinæum. At this juncture, suddenly, without warning, convulsions, beginning in the muscles of the face and neck and gradually inrolving those of the rest of the body, occurred to a degree that the patient could hardly be kept in bed. These violent muscular contractions subsided in about five minutes, and were followed by insensibility with some degree of stertor. About this time the child was brought into the world. It was smali in size, and did not inspire till the warm bath and artificial inflation were employed. The placents was expelled soon after the child; 